doubt remains. Antibiotic treatment may produce considerable benefit.

Little can be done at present to prevent the increased likelihood of gall stones, ${ }^{14}$ though if renal or ureteric stones ${ }^{15}$ develop owing to hyperoxaluria a low-fat and low-oxalate diet may help.

Most patients can have a satisfactory life after small bowel resection, but regular and informed surveillance is essential.

\footnotetext{
${ }^{1}$ Backman, L, and Hallberg, D, Acta Chirurgica Scandinavica, 1974, 140, 57. 2 Newcomer, A D, and McGill, D B, Gastroenterology, 1966, 51, 481.

${ }^{3}$ Corcino, J J, Waxman, S, and Herbert, V, American fournal of Medicine, $1970,48,562$.

${ }^{4}$ Borgström, B, Lundh, G, and Hoffmann, A, Gastroenterology, 1963, 45, 229.

Klipstein, F A, Bulletin of the New York Academy of Science, 1966, 42, 638.

6 Newcomer, A D, and McGill, D B, Gastroenterology, 1966, 51, 481.

7 Bury, K D, Surgery, Gynecology and Obstetrics, 1972, 135, 177.

${ }^{8}$ Hislop, I G, and Grant, A K, Medical fournal of Australia, 1970, 2, 963.

${ }^{9}$ Kalser, M H, et al, Gastroenterology, 1970, 38, 605.

${ }^{10}$ Compston, J E, and Creamer, B, Quarterly fournal of Medicine, 1977, 46, 485.

11 Goode, A, et al, Lancet, 1976, 1, 122

12 Straus, E, Gerson, C, and Yalow, R S, Gastroenterology, 1974, 66, 175.

${ }^{13}$ Compston, J E, et al, Lancet, 1978, 1, 9.

14 Heaton, K W, and Read, A E, British Medical fournal, 1969, 3, 494

15 Dowling, R H, Rose, G A, and Sutor, D, Lancet, 1971, 1, 1103.
}

\section{NHS laboratories: the story as before}

Both the work load in individual laboratory disciplines ${ }^{1-3}$ and their medical and technical staffing ${ }^{4-6}$ are still in a state of rapid change. We should not place too much reliance on comparisons or measurements of work load and effort between one laboratory and another, however, since the method of collecting NHS statistics ${ }^{78}$ is open to local interpretation and presentation. Nevertheless, until we introduce, and the professions accept, a more efficient system (perhaps based on the experience ${ }^{9}$ of the Canadians), present methods of collecting data are better than nothing. ${ }^{10}$

Analysis of data from laboratories in England for 1966-74 by Buttolph has shown that when the "request" is taken as the basic unit of work load there has been a continuing dramatic increase in total numbers. The increase in requests received in clinical chemistry, haematology, and bacteriology has been exponential, while in cytology and surgical histology requests have risen linearly with time. Two-thirds of the total work load of laboratories is clinical chemistry and haematology; the average increase of $10 \%$ per annum in chemistry means that the total doubles in seven years, while in haematology the average increase of $5 \%$ per annum implies doubling in 14 years.

During the period under review the number of laboratories carrying out analyses fell by $22 \%$ to 500 , and, though the numbers of medical laboratory technicians grew, the percentage rise was less than that of the work load. During the past decade many observers have confidently predicted a slowing down in the proliferation of laboratory requests. Ail have been confounded; the exception was in 1974, when several external factors applied-strikes, supply difficulties, and the reorganisation of the Health Service-sufficient to account for the reduction in requests. Nevertheless, the latest statistics ${ }^{10}$ seem to indicate another plateau in the inflow of work, though whether this is real or illusory remains to be seen. Projections for the future remain difficult, though simulation models ${ }^{12}$ might provide a more reasonable basis for predictions.
The growth rate in laboratories is a product of both exogenous and endogenous influences, the former arising from clinics, wards, and general practitioners and the latter from the introduction of newer analytical techniques and $\underline{T}$ mechanisation. If growth continues can the laboratory meet the $\frac{3}{8}$ requirements of the future? If we knew the service requirements $\Omega$ more accurately we could plan to provide equipment, $\stackrel{\hookrightarrow}{\Rightarrow}$ staff, laboratories, and finance, but in a period of economic restraint such plans would be unlikely to come to fruition.

Furthermore, with the uncertainty in all aspects of hospital $\frac{\bar{\sigma}}{\bar{T}}$ life there is no guarantee that the traditional roles of both the laboratories and the hospital will not change. The curtailment $\stackrel{\mathbb{Q}}{\square}$ of the hospital building programme must inevitably affect the $\$$ availability of laboratory accommodation for some years ahead. $\overrightarrow{0}$ Rationalisation of the laboratory service has been proposed, ${ }^{13}$ with the suggestion that it should be based on groups of $\vec{\omega}$ specialised units serving a population of $500000-700000$. Oे Reorganisation on these lines would increase efficiency in the use of both manpower and resources. One step along the route $\vec{\sigma}$ of rationalisation would be the wider development of regional $\overrightarrow{\vec{v}}$ and supraregional services.

1 Whitehead, T P, Annals of Clinical Biochemistry, 1971, 8, 1.

2 Barnard, J F, British Medical fournal, 1976, 1, 383.

3 Rose, H, and Abel-Smith, B, Doctors, Patients, and Pathology. London, Bell, 1972 .

${ }^{4}$ Baron, D N, fournal of Clinical Pathology, 1974, 27, 1013.

5 Greenbury, C L, Fournal of Clinical Pathology, 1971, 24, 551.

6 Lathe, G H, and Mitchell, F L, Lancet, 1966, 1, 1413.

${ }^{7}$ Ministry of Health, Pathology: Measurement of W'ork in Units. London, $\subseteq$ HMSO, 1963.

${ }^{8}$ Ministry of Health, Revision of Pathology Statistics, Hospital Memorandum 64 (82), 1964.

9 Statistics Canada: Canadian Schedule of Unit Values for Clinical Laboratory Procedures. Ottawa, 1975.

10 Johnstone, J H, in Recent Advances in Clinical Biochemistry, ed K G M M Alberti. Edinburgh, Churchill Livingstone, 1978.

11 Buttolph, M A, Fournal of Clinical Pathology, 1977, 30, 1103

12 Peat, Marwick, Mitchell, and Co, Pathology Laboratory Simulation Model. Department of Health and Social Security Project. London, 1973.

${ }^{13}$ Goldberg, I J L, and Mitchell, F L, Lancet, 1970, 2, 1240.

\section{Use of laparoscopy in liver disease}

Despite its wide acceptance throughout Europe the use of laparoscopy in patients with liver disease has not yet found general favour among British gastroenterologists. Nevertheless, $\widetilde{\sim}$ with further evidence both from the United States, ${ }^{1}$ where again the procedure is not widely practised, and from Britain, ${ }^{2} 3$ a re-evaluation of the technique is surely justified.

In their series of 55 patients from New York Friedman and Wolff ${ }^{1}$ found that it was diagnostically useful in 52 cases, using laparoscopy both for visualising the surface and overall appearances of the liver and for guiding liver biopsy by direction of the needle towards visibly abnormal areas. Balfour $^{2}$ reported a similar success rate, using the rather less conventional general (rather than local) anaesthetic, and the King's College Hospital group ${ }^{3}$ found that laparoscopy contributed useful information in the management of 110 of 170 consecutive patients. Laparoscopy is simple to perform, and even in the sick and elderly it is safer than most of the other alternative diagnostic techniques. The equipment is relatively inexpensive-at least in contrast with many other examples of high technology medicine. Hospitals with gynaecological departments are likely already to have a laparoscope, so that hesitancy by gastroenterologists to accept 
the technique is most likely to be due to doubt about its exact place among the diagnostic procedures available.

Laparoscopy allows the operator to inspect the exterior surface of the liver, and, with the aid of a probe, most of the inferior surface. Simple visualisation of the liver without biopsy may be all that is needed to establish a diagnosis of macronodular cirrhosis; whereas the histological findings in a biopsy specimen, if it happens to be taken from the centre of a large regeneration nodule showing apparently normal liver, may be misleading. In one series the histological appearances of biopsy specimens gave false-negative results in up to $30 \%$ of patients later shown to have cirrhosis. ${ }^{4}$ Distinguishing cirrhosis from severe hepatic fibrosis may be difficult from biopsy specimens alone, and in some patients biopsy will be contraindicated because of a prolonged prothrombin time. In all these visualisation of the surface of the liver at laparoscopy may be helpful.

The real advantage from laparoscopy, however, is the possibility of being able to carry out a guided biopsy under direct vision; this is especially true in the diagnosis of intrahepatic malignancy. With laparoscopy and guided biopsy false-negative results have been obtained in only $11 \%$ of patients subsequently found to have intrahepatic tumour, ${ }^{1}$ compared with reported figures of $40-60^{\circ}$ ") using conventional percutaneous biopsy." The success of the procedure depends on the tumour's being visible on the surface of the liver, for lesions deep within its substance will not be visible-though they may be identifiable with ultrasound or isotope scanning, providing another basis for guiding the needle. Nevertheless, if the liver surface is visibly abnormal then laparoscopy allows a much fuller assessment than would otherwise be possible. Peritoneal seedlings may be seen, for example, and the patient saved the discomfort of a laparotomy; a tumour may be visible in only one lobe of the liver, raising the possibility of a partial resection; occasionally, in the case of metastases within the liver, the primary tumour may be seen in the stomach or colon.

A further important use of laparoscopy is in the patient with a primary hepatoma being considered for transplantation: extrahepatic spread is easy to detect and is a clear indication for chemotherapy rather than surgery. Diffuse lesions of the liver such as infectious hepatitis or active chronic hepatitis may also be recognised at the time of laparoscopy-but in these cases the diagnostic yield is probably no higher than with conventional percutaneous liver biopsy. Furthermore, there is no evidence to suggest that if the prothrombin time is prolonged a liver biopsy is any less hazardous when performed under direct vision at laparoscopy. Direct pressure on the biopsy site may not always prevent haemorrhage, and not all endoscopy units have facilities for diathermy coagulation.

The value of laparoscopy in investigating patients with obstructive jaundice is more controversial. Immediate preoperative laparoscopy with laparoscopic cholangiography has been advocated for visualising the biliary tree in all patients ${ }^{6}$ with obstructive jaundice. In most instances, however, such excellent results are obtained using percutaneous cholangiography with the Okuda needle ${ }^{7}$ that there is seldom a need for taking up time in the operating theatre with this alternative technique. Its justification is that when an intrahepatic tumour (such as a cholangiocarcinoma) is causing the biliary obstruction the diagnosis can be made at laparoscopy even though it may not be suspected using percutaneous cholangiography. Care is necessary, however-especially in long-standing obstructive jaundice-not to mistake cystic dilatation of the bile ducts for hepatic metastases.

Without doubt, gastroenterologists will learn to show the same dexterity with the laparoscope as they have already shown with the gastroduodenoscope and the colonoscope. And undoubtedly, with careful selection of patients, laparoscopy can be of considerable help in the investigation of patients with liver disease.

${ }^{1}$ Friedmann, I H, and Wolff, W I, American fournal of Gastroenterology, 1977, 67, 319.

Balfour, T W, Lancet, 1976, 1, 612

Woolf, I L, and Williams, R, Lancet, 1976, 1, 807.

Soloway, R D, et al, American fournal of Digestive Diseases, 1971, 16, 1082.

Jori, G P, and Peschle, C, Gastroenterology, 1972, 63, 1016.

${ }^{6}$ Cuschieri, A, Annals of the Royal College of Surgeons, 1975, 57, 33.

' Okuda, K, et al, American fournal of Digestive Diseases, 1974, 19, 21.

\section{Antacids and brucellosis}

Sir Arthur Hurst once suggested ${ }^{1}$ that no one with established achlorhydria should serve in the tropics because of the increased liability to intestinal infections. Though gastric juice is bactericidal for vegetative bacteria (other than tubercle bacilli), we have little information about differences in their susceptibility. Using hydrochloric acid, Garrod ${ }^{2} 3$ carried out studies with and without thiocyanate, an element in saliva which contributes to its action, and natural resting gastric juice of different acid contents, acting both alone and in the presence of different amounts of milk. He found there was a clear order of susceptibility over a wide range among the bacteria examined, much the most easily killed being Brucella spp (abortus rather more so than melitensis). Typhoid bacilli showed an intermediate degree of susceptibility, and dysentery bacilli (Shigella flexneri and sonnei) were far more resistant, surviving exposure to gastric juice for two hours under conditions in which $\mathrm{Br}$ abortus was killed in less than one minute.

These findings tallied with the clinical information on the attack rate of the bacterial infections: very high in bacillary dysentery, intermediate in typhoid fever (in a water-borne outbreak usually less than $10 \%$ ), and very low indeed in undulant fever. Between the wars, when this study was done, contagious abortion was widespread and much more raw milk was consumed than today. Millions of people in Britain must at some time have drunk infected milk, but the number of cases of brucellosis diagnosed annually was a few hundred at most, and some of these in farm workers and others in direct contact with infected cattle.

The gastric barrier is only one of several factors which will determine whether infection results from exposure. It will be decisive if bactericidal action is complete, but bacteria successfully traversing the stomach still depend on their capacity to invade and establish themselves in the tissues, and this capacity may well be lower in Brucella spp than in other pathogens, at least when the mouth is the portal of entry. Percutaneous entry, to which farmers and veterinarians are liable, has been shown experimentally to result in disease more often. ${ }^{4}$

Since Garrod proposed that "the infectivity of intestinal pathogens varies with their resistance to bactericidal action in the stomach" there has been no systematic study of gastric secretory function in sufferers from undulant fever, and this could well be inconclusive even were it carried out, since achlorhydria is often temporary, and may have emotional as well as physical causes. ${ }^{56}$ After the lapse of so many years, during which this belief has not gained general acceptance, some new support for it has come from an unexpected direction. Steffen ${ }^{7}$ has recently reported two cases of undulant fever, each patient being the only affected member of groups 